\title{
Incidence of traumatic spinal cord injury in Italy during 2013-2014: a population-based study
}

\author{
S Ferro ${ }^{1,2}$, L Cecconi ${ }^{3}$, J Bonavita ${ }^{4}$, MC Pagliacci $^{5}$, A Biggeri $^{3}$ and M Franceschini ${ }^{6,7}$ for the Italian SCI \\ Study Group ${ }^{8}$
}

Study design: Observational prospective population-based incidence study.

Objectives: The main objective of this study was to assess the incidence of traumatic spinal cord injuries (TSCls) and incidence rates, in order to provide estimates by age, gender, characteristics and cause.

Setting: This study was conducted at acute-care spinal cord injury (SCl) hospitals and SCl centers from 11 Italian regions, between 1 October 2013 and 30 September 2014.

Methods: Data of all consecutive patients with acute TSCI who met the inclusion criteria were obtained through case reporting by clinicians. The data were collected into a web database. Incidence rates and incidence rate ratios were calculated and stratified by age, gender, cause, level and completeness.

Results: From 50\% of the entire population of Italy, 445 new cases of TSCI were included. The crude incidence rate of TSCI was 14.7 cases per million per year (95\% Cl: 13.4-16.4); the overall male to female ratio was 4:1 and the mean age was 54. Complete information was available in $85 \%$ of the sample and revealed tetraplegia in $58 \%$ and incomplete lesion in $67 \%$ of cases. The leading cause of TSCI was falls (40.9\%) followed by road traffic accidents (33.5\%). The leading cause was falls for patients over 55 and road traffic accidents for patients under 55.

Conclusion: The changing trend of TSCl epidemiology concerns the increase in the average age of TSCI people and the increase of both cervical and incomplete lesions. The etiology shows the primacy of falls over road traffic accidents and suggests the need for a change in prevention policies.

Spinal Cord (2017) 55, 1103-1107; doi:10.1038/sc.2017.88; published online 5 September 2017

\section{INTRODUCTION}

Reliable and up-to-date data on the incidence of traumatic spinal cord injury (TSCI) are critical to monitor the causes of trauma and their changes over the past years. They are also important to focus on preventive measures and health-care planning. Only one study specifically addressed the incidence of TSCI in Italy. It was retrospective, geographically restricted, not up-to-date and focused on a limited population. ${ }^{1}$ In addition, over the past two decades, prospective studies $^{2,3}$ have been based only on rehabilitation settings.

With regard to other countries, in Western Europe, TSCI incidence was calculated by means of either the hospital discharge forms, the International Classification of Diseases (ICD) codes of classification or the examination of the medical records, thus resulting in a retrospective data collection over long periods of time. TSCI incidence rates vary from 10.2 cases per million per year to 23.5 cases per million per year. ${ }^{6-10}$ In North America, the estimated TSCI incidence ranges from 40 to 56 cases per million per year. ${ }^{4,5}$

The trend in the United States suggests a variation in the bimodal distribution of the age of patients with TSCI, with an increase in the population with SCI at a later age (over 60), with a greater likelihood of discharge to a nursing home and subsequent higher costs for the healthcare system. Furthermore, incomplete lesions are increasing and etiology is shifting toward a higher percentage of ground level falls as compared with the levels in road traffic accidents, especially in older population. ${ }^{4,11}$

The same is already occurring in Japan, where $75 \%$ of persons with SCI are tetraplegic and predominantly aged people, ${ }^{12}$ when compared with the $47 \%$ in North America and Australia and the 51\% in Western Europe. ${ }^{13}$ Calculating the incidence and its changes over years is, therefore, necessary for a correct allocation of resources both for prevention and for acute and rehabilitation care.

Italy is included in the list of the most developed countries. For this reason, we might hypothesize that the trend of TSCI incidence in Italy might be similar to the one of other nations of this group. With this observational prospective study, based on a large population, distributed across the whole country, we aim to determine the incidence of TSCI in Italy and describe its characteristics in terms of etiology, characteristics of the lesion and demographic characteristics of the population, with specific attention to the peculiar features of our country.

\footnotetext{
${ }^{1}$ Age.Na.S., National Agency for Regional Health Services, Rome, Italy; ${ }^{2}$ Department of Hospital Services, Emilia-Romagna Regional Health Authority, Emilia-Romagna, Italy; ${ }^{3}$ Department of Statistics, University of Florence, Florence, Italy; ${ }^{4} \mathrm{SCl}$ Unit, Montecatone Rehabilitation Institute, Imola, Bologna, Italy; ${ }^{5} \mathrm{SCl}$ Unit, Perugia Hospital, Perugia, Italy; ${ }^{6}$ Department of Neurorehabilitation, IRCCS San Raffaele Pisana, Rome, Italy and ${ }^{7}$ San Raffaele University, Rome, Italy

${ }^{8}$ The members of the Italian SCI Study Group Steering Committee are listed before references.

Correspondence: Dr J Bonavita, SCI Unit, Montecatone Rehabilitation Institute, Via Montecatone 37, Imola, Bologna 40026, Italy.

E-mail: jacopo.bonavita@montecatone.com

Received 14 April 2017; revised 19 June 2017; accepted 22 June 2017; published online 5 September 2017
} 


\section{METHODS}

A prospective incidence study was developed on the basis of medical case reporting of patients with TSCI admitted to acute-care (emergency department, spinal cord injury center, neurosurgery and intensive care unit) and post-acutecare (spinal cord injury rehabilitation) centers from 11 Italian regions (Table 1), between 1 October 2013 and 30 September 2014.

Age.Na.S. (National Agency for Regional Health Services) created a regional network for a systematic collection of data.

Participation in the study required that all available regions would fulfill the following conditions:

- Census of all acute-care TSCI centers and interest of physicians involved in the management of TSCI;

- Training of the medical staff responsible for case reporting about a consistent clinical evaluation of TSCI, with a specific course according to the International Standards of Neurological Classification of SCI (ISNCSCI).

- A regional clinical coordinator who would gather the data and send them to the national collection center. In case of doubt concerning inclusion/ exclusion, an audit involving the regional clinical coordinator and expert physicians was carried out.

All consecutive patients with acute TSCI admitted to hospitals and resident in a participating region were included in the study. TSCI patients were either admitted in SCI units and rehabilitation centers, which are expert in diagnosing and treating SCI patients, or in emergency department, neurosurgery or ICU, and seen by physiatrists, who, likewise, are expert in SCI. Data were collected at the first hospital admission after injury. A TSCI case was defined, for the purpose of this study, as a new hospital admission caused by an acquired traumatic lesion of the spinal cord or cauda equina, resulting in a complete or partial, transient or permanent loss of motor, sensory, bladder or bowel function below the level of the lesion, occurring in the study period.

An etiological classification of the lesion was performed according to the International Spinal Cord Injury Core Data Set. ${ }^{14}$ The ISNCSCI was adopted to assess the level and completeness of the lesion. ${ }^{15} \mathrm{~A}$ web database was created. It included a form for the collection of the following data: the presence of a clinically documented TSCI, gender, age, level and completeness of the injury, cause and date of the injury, admission date and discharge date.

Each regional coordinator inserted into the database all new TSCI consecutive cases diagnosed in the observation period, related to residents in the participating regions and reported by the centers involved.

A formal trial Steering Committee was established in order to ensure a periodic evaluation of study enrollment and completeness and homogeneity of the information collected, and to face any critical issues arising during the study period. The study obtained the endorsement of FAIP (Italian Federation of Paraplegics and Tetraplegics Associations), which contributed to develop the study plan.

The study was approved and funded by the Italian Ministry of Health.

\section{Statistical analysis}

Standard descriptive statistics were conducted to summarize data with respect to the demographic and TSCI characteristics. Neurological lesion levels were dichotomized into tetraplegia (C1-C8) and paraplegia (T1-S5).

Annual incidence rates were calculated using the Italian population living in the regions participating in the TSCI incidence study. Data on the Italian resident population on 1 January 2014 were retrieved from ISTAT (National Institute of Statistics) and were stratified by age, gender and municipalities. A two-tailed $P$-value less than 0.05 was considered significant. All analyses were performed using STATA Version 13.1 for Windows (College Station, TX, USA).

\section{RESULTS}

Eleven out of the 20 Italian regions participated in the TSCI incidence study (Emilia-Romagna, Friuli Venezia Giulia, Liguria, Lombardy, Marche, Piedmont, Puglia, Sicily, Tuscany, Umbria and Veneto).

Some regions contributed only with part of the population, limited to the territories (provinces) that could comply with the data collection requirements. Therefore, the population (henceforth 'study population') on which the incidence was calculated was about 30 million (corresponding to $\sim 50 \%$ of the entire Italian population). In this population, 445 TSCI cases were registered (Table 1). The crude incidence rate of TSCI was 14.7 cases per million per year (95\% CI: 13.4-16.4). The incidence of TSCI was consistently higher for males than for females, namely $94(21 \%)$ were females and $351(79 \%)$ were males. The overall annual incidence rate was 24.0 (95\% CI: 21.5-26.6) for males and 6.0 (95\% CI: 4.9-7.4) for females, yielding an overall incidence rate ratio of 4.0 (95\% CI: 3.1-5.0) $(P<0.001)$. The age group with the highest rate ratio was $45-54$, while the age group with the lowest rate ratio was $<15$. The highest estimated annual incidence rate was registered in the 75-84 age group, with 50.2 (95\% CI: 37.4-66.0) for males and 15.6 (9.8-23.6) for females (Table 2 and Figure 1).

The overall average age was 54 years $($ s.d. $=20.5)$. The average age was 56 years $($ s.d. $=23.0)$ for females and 53 years $($ s.d. $=19.8)$ for males $(P=0.2508)$.

Informations on neurological lesion level were available in 375 cases (85\%), of which 217 (58\%) suffered from tetraplegia and 158 (42\%) from paraplegia. Informations on AIS classification were available on 360 cases $(82 \%)$ and $67 \%$ were incomplete lesions (Table 3).

The description of the cause of the trauma was available for 386 cases $(87 \%)$ and showed falls as the leading cause $(40.9 \%)$ followed by road traffic accidents (33.5\%) (Table 4). Notably, falls were the leading cause among persons over 55 years of age, while road traffic accidents

Table 1 Incidence (cases per million per year) in the 11 Italian regions participating in the TSCl incidence study

\begin{tabular}{|c|c|c|c|c|c|}
\hline Region & Population & Study population & Number of cases & Incidence (cases/million) & Study coverage \\
\hline Emilia-Romagna & 4446354 & 4446354 & 82 & $18.4(14.7,22.9)$ & $100 \%$ \\
\hline Friuli-Venezia Giulia & 1229363 & 1229363 & 22 & $17.9(11.2,27.1)$ & $100 \%$ \\
\hline Liguria & 1591939 & 1369562 & 22 & $16.1(10.1,24.3)$ & $86 \%$ \\
\hline Lombardy & 9973397 & 8027403 & 90 & $11.2(9.0,13.8)$ & $80 \%$ \\
\hline Marche & 1553138 & 1164974 & 20 & $17.2(10.5,26.5)$ & $75 \%$ \\
\hline Piedmont & 4436798 & 4055398 & 51 & $12.6(9.4,16.5)$ & $91 \%$ \\
\hline Puglia & 4090266 & 1261964 & 18 & $14.3(8.5,22.5)$ & $31 \%$ \\
\hline Sicily & 5094937 & 2434844 & 30 & $12.3(8.3,17.6)$ & $48 \%$ \\
\hline Tuscany & 3750511 & 1910328 & 33 & $17.3(11.9,24.3)$ & $51 \%$ \\
\hline Umbria & 896742 & 665217 & 14 & $21.0(11.5,35.3)$ & $74 \%$ \\
\hline Veneto & 4926818 & 3615485 & 63 & $17.4(13.4,22.3)$ & $73 \%$ \\
\hline Italy & 60782668 & 30180892 & 445 & $14.7(13.4,16.2)$ & $50 \%$ \\
\hline
\end{tabular}


were the main cause for people under 55 years of age (Table 5). A significant proportion of falls $(36.8 \%)$ was not from height, but occurred at ground level. Missing data about neurological lesion level, completeness and etiology were uniformly distributed in all regions and centers.

\section{DISCUSSION}

Our study allowed us, for the first time in our country, to collect TSCI incidence data on a large number of people. There are several important aspects to consider. First of all, we collected data on the general population in a prospective way, ensuring the highest level of uniformity among the clinicians responsible for case reporting, thanks to a specific training course of medical staff about a consistent clinical evaluation of TSCI. This allowed us to gather data without confounding factors, unlike other works of literature that used national information systems on a retrospective basis. Second, for the purposes of this study, TSCI was defined according to clinical standards, specifically, it was recognized and diagnosed with at least one clinical assessment by professionals. Third, it was the first experience in Italy with a centralized database, which enabled an extremely clean and homogenous TSCI data collection, thanks to the standardized case reporting and to the Steering Committee's monitoring activity.

Furthermore, our study collects data on more than $50 \%$ of the Italian population and can be considered as representative of the entire Italian population. This is because we uniformly collected data from

Table 2 Age- and gender-specific TSCI incidence (cases per million per year)

\begin{tabular}{llll}
\hline \multirow{2}{*}{ Age/Gender } & $F$ (incident cases) & $M$ (incident cases) & M/F ratio \\
\cline { 2 - 4 } & \multicolumn{1}{c}{$95 \% \mathrm{Cl}$} & $95 \% \mathrm{Cl}$ & $95 \% \mathrm{Cl}$ \\
\hline$<15$ & $1.5(0.3,4.3)$ & $2.8(1.0,6.1)$ & $1.9(0.4,11.7)$ \\
$15-24$ & $6.0(2.6,11.7)$ & $25.2(17.7,34.9)$ & $4.2(1.9,10.6)$ \\
$25-34$ & $5.5(2.5,10.4)$ & $20.4(14.1,28.5)$ & $3.7(1.8,8.9)$ \\
$35-44$ & $4.7(2.4,8.5)$ & $18.3(13.3,24.7)$ & $3.9(2.0,8.3)$ \\
$45-54$ & $4.2(2.0,7.7)$ & $29.3(22.8,37.0)$ & $7.0(3.6,15.2)$ \\
$55-64$ & $5.2(2.5,9.5)$ & $25.3(18.5,33.7)$ & $4.9(2.4,10.9)$ \\
$65-74$ & $9.6(5.6,15.3)$ & $36.3(27.5,47.1)$ & $3.8(2.2,7.0)$ \\
$75-84$ & $15.6(9.8,23.6)$ & $50.2(37.4,66.0)$ & $3.2(1.9,5.6)$ \\
$>84$ & $5.8(1.6,14.8)$ & $30.1(13.8,57.2)$ & $5.2(1.5,23.2)$ \\
Total & $6.0(4.9,7.4)$ & $24.0(21.5,26.6)$ & $4.0(3.1,5.0)$ \\
\hline
\end{tabular}

regions in the North, Center and South of Italy. Moreover, spinal lesions are usually centralized to trauma centers and specialized departments, which, as a matter of fact, have been involved in the study. It is undoubtedly a qualitative leap with respect to previous national experiences in which data were collected mainly from North Italy. ${ }^{2,3}$ This is also a clear sign of the diffusion of more homogenous standards in the management of TSCIs from emergency to rehabilitation on the national territory in the past two decades.

The estimated incidence of TSCI in Italy was comparable to that of other Western European countries, ${ }^{8-10}$ whereas it is lower than that of other countries, such as Spain. ${ }^{7}$

The characteristics of our study design enable us to state that although our data are unlikely to be overestimated, underestimation might be possible. As a matter of fact, casualties at the scene of the accident were not included, as emergency services were not involved in case reporting. We do not know how significant these data could be on the total incidence rate, but, according to a recent work which included casualties at the scene of the accident site, they may possibly double the incidence rate. ${ }^{16}$

The high average age (54 years) is another significant aspect. Our data describe a trend which has been already highlighted in literature, with an increase in incidence rates among the elderly, more striking than in other countries. ${ }^{6,9,12}$ These figures could be heavily affected by the increase in the average age of the general Italian population and, therefore, by the increased risk of falling for this particular group of people.

Another peculiar aspect of our survey is the significant risk $(\mathrm{IRR}=4)$ of TSCI for males. In particular, the highest ratios are reported in the 45-54 and 55-64 age groups, whereas, as regards the very young ( $<15$ years), the ratio between males and females is little more than $1: 1$.

In comparison with the international literature, our data are consistent, if not higher, ${ }^{8,9}$ with the trend according to which an increase of tetraplegia and incomplete injuries has been recorded in the past decades.

With regard to the leading causes of TSCI, we are also in line with the most recent contributions in literature of the highly developed countries, which record an increase of falls over road traffic accidents. ${ }^{10}$ If compared with the only Italian study, which dates back two decades ago and was not representative of the entire population, but only of TSCIs accessing rehabilitation, our study shows a clear change in the etiology, with falls now outweighing road traffic

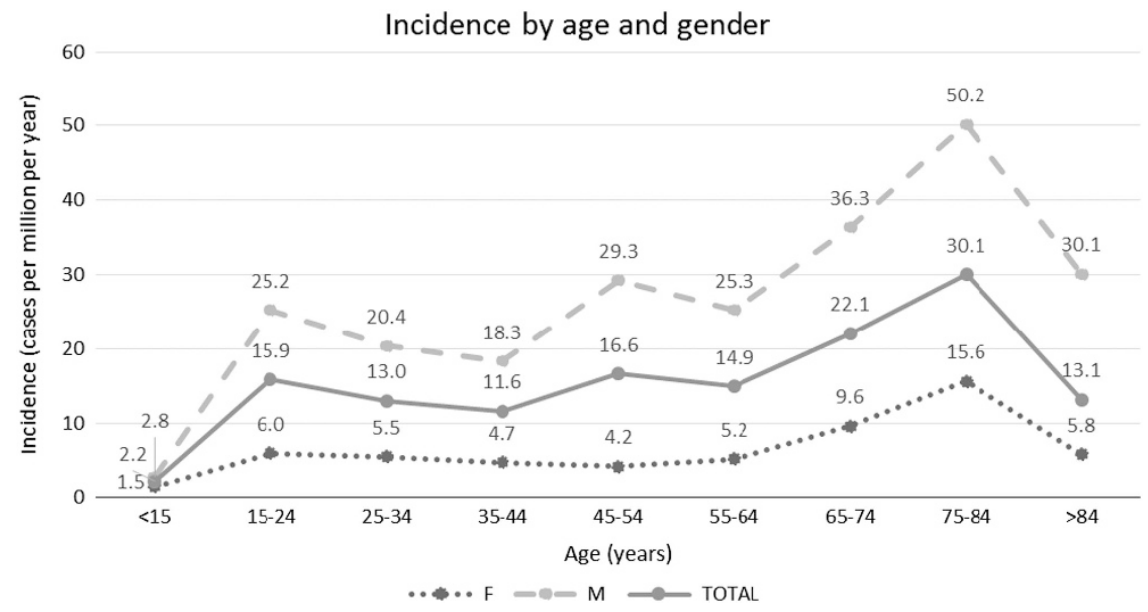

Figure 1 Age- and gender-specific TSCI incidence (cases per million per year). 
accidents (which at that time accounted for more than 50\% of injuries). There is also a difference in the distribution by age groups of TSCI population and in the greater number of incomplete lesions., This has important implications for prevention, as regards both the target population and the settings in which prevention programs have to be implemented. The fact that more than one-third of falls does not occur from heights (scaffolding, trees and so on) but at ground level, represents a different type of trauma, with the result that prevention in workplaces, such as construction sites, must be supported by greater attention to domestic accidents, especially for an older target population.

Missing and/or not assessable data regarding the neurological picture (level and completeness of the injury according to ISNCSCI and AIS standards) and the etiology did not allow us to explore any correlations with other data. As a matter of fact, the presence of 'nottestable' patients with confirmed TSCI is established on clinical grounds, which make it impossible to complete an examination by

Table 3 Association between lesion level and severity in TSCI cases

\begin{tabular}{lccc}
\hline AlS & Paraplegia & Tetraplegia & Total \\
\hline A & $72(45.6 \%)$ & $53(24.4 \%)$ & $125(33.3 \%)$ \\
B & $17(10.8 \%)$ & $37(17.1 \%)$ & $54(14.4 \%)$ \\
C & $40(25.3 \%)$ & $63(29.0 \%)$ & $103(27.5 \%)$ \\
D & $22(13.9 \%)$ & $56(25.8 \%)$ & $78(20.8 \%)$ \\
NT & $7(4.4 \%)$ & $8(3.7 \%)$ & $15(4.0 \%)$ \\
Total & 158 & 217 & 375 \\
\hline
\end{tabular}

Table 4 Specific causes of TSCI

\begin{tabular}{lrc}
\hline Etiology & $\mathrm{n}$ & $\%$ \\
\hline Fall & 182 & $40.9 \%$ \\
From height & 115 & $25.8 \%$ \\
From ground level & 67 & $15.1 \%$ \\
Road traffic accident & 149 & $33.5 \%$ \\
Car & 54 & $12.1 \%$ \\
Motorcycle & 53 & $11.9 \%$ \\
Pedestrian/Bicycle & 42 & $9.4 \%$ \\
Sports/Leisure & 29 & $6.5 \%$ \\
Sport accident & 20 & $4.5 \%$ \\
Diving & 9 & $2.0 \%$ \\
Violence & 15 & $3.4 \%$ \\
Stab wound & 13 & $2.9 \%$ \\
Gunshot wound & 2 & $0.4 \%$ \\
Others & 11 & $2.5 \%$ \\
NT & 59 & $13.3 \%$ \\
\hline
\end{tabular}

the international neurological standards. Missing data can also depend on the fact that the first case report was not always performed by physicians expert in ISNCSCI. For that very reason, a very simple casereport form was adopted to encourage the maximum collaboration of the professionals involved and the thoroughness of 'new case' reporting, even at the expense of accuracy and completeness of initial neurological assessment and detailed medical history of trauma. On the other hand, missing data are uniformly distributed in all regions and centers, so it can be assumed that ISNCSCI, AIS and etiology percentages are not influenced by those missing data.

\section{Limitations}

We were unable to cover the entire national territory because some regions did not join the network and some others contributed only partially.

Another limitation concerns the observation period, which covered only 1 year. That might reflect a certain variability that might be reduced by doing a study over several years.

Perhaps our underestimation is due to unrecognized mild cases which may have escaped the network (and which rapidly evolve towards AIS E) and cases of complex traumas (Traumatic Brain Injury and SCI, polytrauma) that, after admission to intensive care, take different paths or have a high mortality within the first hour.

Another weakness of the study is the exclusion of the emergency services from the network: deaths within the first hour have been overlooked.

The number of missing data in reported cases, together with that of not-testable acute patients, may result in a weakness for the description of the sample as regards the neurological characteristics and the etiology of the study. We know, however, that the number of nottestable patients with acute ISNCSCI classification in an acute phase can be significant. ${ }^{17}$

\section{CONCLUSIONS}

The collection of prospective data allowed us for the first time to define the incidence of TSCI in Italy, whose values are in line with the average ones of the Western European countries with which we share most of the characteristics of the population and the socio-economic features. The changing trend of TSCI epidemiology in recent decades, already known from literature, has been confirmed in Italy, with an increase in the average age of people affected by TSCI and the increase of both incomplete and cervical lesions. The collection of data about etiology indicates for the first time the primacy of falls over road traffic accidents, with a correlation between these causes and age which would require an in-depth analysis, but also suggests the need for a strengthening of prevention policies, with the identification of prevention campaigns, different from those of the past and specifically addressed to the elderly. ${ }^{18}$ Alongside with policies promoting 'active

Table 5 Specific causes of TSCI by age

\begin{tabular}{|c|c|c|c|c|c|c|c|c|c|c|}
\hline Etiology & $<15$ & $15-24$ & $25-34$ & $35-44$ & $45-54$ & $55-64$ & $65-74$ & $75-84$ & $>84$ & Total \\
\hline Fall & $0.0 \%$ & $2.7 \%$ & $3.4 \%$ & $3.4 \%$ & $5.2 \%$ & $6.3 \%$ & $8.5 \%$ & $9.7 \%$ & $1.8 \%$ & $40.9 \%$ \\
\hline Road traffic accident & $0.4 \%$ & $4.9 \%$ & $4.0 \%$ & $6.1 \%$ & $6.7 \%$ & $4.3 \%$ & $4.5 \%$ & $2.2 \%$ & $0.2 \%$ & $33.5 \%$ \\
\hline Sports/Leisure & $0.0 \%$ & $0.2 \%$ & $0.4 \%$ & $0.4 \%$ & $1.1 \%$ & $0.4 \%$ & $0.7 \%$ & $0.0 \%$ & $0.0 \%$ & $3.4 \%$ \\
\hline Violence & $0.4 \%$ & $1.1 \%$ & $0.9 \%$ & $0.4 \%$ & $2.2 \%$ & $0.7 \%$ & $0.2 \%$ & $0.4 \%$ & $0.0 \%$ & $6.5 \%$ \\
\hline Others & $0.2 \%$ & $0.0 \%$ & $0.2 \%$ & $0.4 \%$ & $0.7 \%$ & $0.2 \%$ & $0.0 \%$ & $0.7 \%$ & $0.0 \%$ & $2.5 \%$ \\
\hline NT & $0.9 \%$ & $0.9 \%$ & $0.7 \%$ & $1.3 \%$ & $1.8 \%$ & $0.7 \%$ & $2.7 \%$ & $3.4 \%$ & $0.9 \%$ & $13.3 \%$ \\
\hline Total & $2.0 \%$ & $9.9 \%$ & $9.7 \%$ & $12.1 \%$ & $17.8 \%$ & $12.6 \%$ & $16.6 \%$ & $16.4 \%$ & $2.9 \%$ & $100.0 \%$ \\
\hline
\end{tabular}


ageing', whose aim is to enhance the quality of life as people age, it is necessary to implement preventive policies addressing the needs of the 'fragile' elderly with particular attention to the prevention of falls.

\section{DATA ARCHIVING}

There were no data to deposit.

\section{CONFLICT OF INTEREST}

The authors declare no conflict of interest.

\section{ACKNOWLEDGEMENTS}

This study was financed within the framework of the 2012 CCM Program. CCM is the National Centre for Disease Prevention and Control whose task is to liaise with the Ministry of Health and the regional governments as far as surveillance and prevention are concerned and whose aim is to promptly respond to emergencies. http://www.ccm-network.it/progetto.jsp?id = node/ 1846\&idP $=740$

\section{MEMBERS OF THE ITALIAN SCI STUDY GROUP STEERING COMMITTEE}

S Ferro ${ }^{1,2}$, M Bellentani ${ }^{1}$, M Franceschini ${ }^{6,7}$, A Cavina ${ }^{4}$, J Bonavita ${ }^{4}$ MC Pagliacci ${ }^{5}$, A Biggeri ${ }^{3}$, L Cecconi ${ }^{3}$, F De Iure ${ }^{9}$, G Gordini $^{9}$, T Redaelli ${ }^{10}$, MV Actis ${ }^{11}$, G Del Popolo ${ }^{12}$, G Bertagnoni ${ }^{13}$, R Avesani ${ }^{14}$ and V Falabella ${ }^{15}$

${ }^{9} \mathrm{SCI}$ Surgery Unit and Intensive Care Unit, Maggiore Hospital, Bologna, Italy; ${ }^{10} \mathrm{SCI}$ Unit, Niguarda Hospital, Milan, Italy; ${ }^{11} \mathrm{SCI}$ Unit, Città della Salute e della Scienza Hospital, Turin, Italy; ${ }^{12}$ SCI Unit, Careggi Hospital, Florence, Italy; ${ }^{13} \mathrm{SCI}$ Unit, San Bortolo Hospital, Vicenza, Italy; ${ }^{14}$ Department of Neurorehabilitation, Don Calabria Hospital, Negrar, Verona, Italy and ${ }^{15}$ FAIP, Italian Federation of Paraplegics and Tetraplegics Associations, Rome, Italy.

\section{COLLABORATING HOSPITALS AND REGIONAL HEALTH AUTHORITIES}

MV Actis ${ }^{11}, \mathrm{M}_{\text {Stillittano }}{ }^{11}$, S Petrozzino ${ }^{16}, \mathrm{C}_{\text {Cisari }}{ }^{17}, \mathrm{M} \mathrm{Salvini}^{18}$, T Redaelli $^{10}$ $\mathrm{R} \operatorname{Tosi}^{10}, \mathrm{CM}$ Borghi $^{19}, \mathrm{~A} \mathrm{Bava}^{19}$, C Pistarini ${ }^{20}, \mathrm{G}_{\text {Molinero }}{ }^{21}$, A Signorelli ${ }^{21}$, S Sandri ${ }^{22}$, F Simeoni ${ }^{23}$, M Brambilla ${ }^{24}$, MA Banchero ${ }^{25}$, A Olivero $^{25}$, G Zanaboni ${ }^{25}$, R Avesani ${ }^{14}$, G Bertagnoni ${ }^{13}$, M Leucci ${ }^{13}$, L Lain ${ }^{13}$, M Saia ${ }^{26}$, A Zampa $^{27}$, P Del Fabro ${ }^{27}$, M Saccavinin ${ }^{28}$, A Fanzutto ${ }^{29}$, A Massone ${ }^{30}$, J Bonavita ${ }^{4}, \mathrm{D}$ Gaddoni ${ }^{4}$, S Olivi ${ }^{4}, \mathrm{G}_{\text {Musumeci }}{ }^{4}$, R Pederzini ${ }^{4}, \mathrm{HC}^{3} \mathrm{Bazo}^{31}$, D Nicolotti ${ }^{31}, \mathrm{M} \mathrm{Nora}^{32}$, R Brianti ${ }^{32}$, C Iaccarino ${ }^{32}$, A Volpi ${ }^{32}$, A Lombardi ${ }^{33}$ S Cavazza $^{33}$, F Casoni ${ }^{33}$, F De Iure ${ }^{9}$, G Gordini ${ }^{9}$, R Piperno ${ }^{9}$, G Teodorani ${ }^{34}$, A Naldi ${ }^{34}$, G Vergoni ${ }^{34}$, E Maietti $^{35}$, A Botti ${ }^{42}$, S Ferro ${ }^{1,2}$, G Pagoto $^{2}$, G Del Popolo ${ }^{12}$, M Moresi ${ }^{12}$, M Postiglione ${ }^{12}$, C Bini ${ }^{12}$, M Tagliaferri ${ }^{36}$, MA Recchioni ${ }^{37}$, P Pelaia ${ }^{37}$, L Di Furia ${ }^{38}$, MC Pagliacci ${ }^{5}$, R Maschke ${ }^{5}$, L Caruso $^{5}$, L Speziali ${ }^{5}$, M Zenzeri ${ }^{39}$, P Fiore ${ }^{40}$, R Marvullii" ${ }^{40}$ R Nardulli ${ }^{41}$, C Lanzillotti ${ }^{42}$, M Ruccia $^{43}$, MP Onesta ${ }^{44}$, T Di Gregorio ${ }^{44}$, F Franchina ${ }^{45}$, MG Furnari ${ }^{46}$, C Pilati ${ }^{47}$, MMerafina ${ }^{47}$, F Crescia ${ }^{47}$, D Fletzer ${ }^{48}$, G Scivoletto ${ }^{49}$ and N Di Lallo ${ }^{50}$

${ }^{16}$ Alessandria Hospital, Alessandria, Italy; ${ }^{17}$ Novara Hospital, Novara, Italy; ${ }^{18}$ Piedmont Region, Italy; ${ }^{19}$ Pini CTO Hospital, Milan, Italy; ${ }^{20}$ IRCCS Maugeri Foundation, Pavia, Italy; ${ }^{21}$ Bergamo Hospital, Bergamo, Italy; ${ }^{22}$ LegnanoMagenta Hospital, Legnano, Milan, Italy; ${ }^{23}$ Garbagnate Hospital, Garbagnate, Milan, Italy; ${ }^{24}$ Valtellina Hospital, Sondalo, Sondrio, Italy; ${ }^{25}$ Lombardy Region, Italy; ${ }^{26}$ Veneto Region, Italy; ${ }^{27}$ Gervasutta Hospital, Udine, Italy; ${ }^{28}$ Palmanova Hospital, Udine, Italy; ${ }^{29}$ Friuli Venezia Giulia Region, Italy; ${ }^{30}$ Santa Corona
Hospital, Pietra Ligure, Savona, Italy; ${ }^{31}$ Villanova d'Arda Hospital, Piacenza, Italy; ${ }^{32}$ Parma Hospital, Parma, Italy; ${ }^{33}$ Baggiovara Hospital, Modena, Italy; ${ }^{34}$ Cesena Hospital, Cesena, Italy; ${ }^{35}$ Ferrara Hospital, Ferrara, Italy; ${ }^{36}$ Tuscany Region, Italy; ${ }^{37}$ Ospedali Riuniti, Ancona, Italy; ${ }^{38}$ Marche Region, Italy; ${ }^{39}$ Umbria Region, Italy; ${ }^{40}$ Bari Hospital, Bari, Italy; ${ }^{41}$ IRCCS Maugeri Foundation, Cassano Murge, Bari, Italy; ${ }^{42}$ IRCCS Maugeri Foundation, Ceglie Messapica, Brindisi, Italy; ${ }^{43}$ Puglia Region, Italy; ${ }^{44}$ Cannizzaro Hospital, Catania, Italy; ${ }^{45}$ Villa Sofia Hospital, Palermo, Italy; ${ }^{46}$ Sicily Region, Italy; ${ }^{47}$ Alesini CTO Hospital, Rome, Italy; ${ }^{48}$ Ostia Hospital, Rome, Italy; ${ }^{49}$ IRCCS S. Lucia Foundation, Rome, Italy and ${ }^{50}$ Lazio Region, Italy.

1 Caldana L, Lucca L. Epidemiological remarks on traumatic spinal cord injuries and non traumatic spinal cord diseases in Veneto 1994-1995. Eur Med Phys 1998; 34: 121-124.

2 Pagliacci MC, Celani MG, Spizzichino L, Zampolini M, Aito S, Citterio et al. Spinal cord lesion management in Italy: a 2-year survey. Spinal Cord 2003; 41: 620-628.

3 Pagliacci MC, Celani MG, Zampolini M, Spizzichino L, Franceschini M, Baratta S et al. An Italian survey of traumatic spinal cord injury. An Italian survey of traumatic spinal cord injury. The Gruppo Italiano Studio Epidemiologico Mielolesioni Study. Arch Phys Med Rehabil 2003; 84: 1266-1275.

4 DeVivo MJ. Epidemiology of traumatic spinal cord injury: trends and future implications. Spinal Cord 2012; 50: 365-372.

5 Selvarajah S, Hammond ER, Haider AH, Abularrage CJ, Becker D, Dhiman N et al. The burden of acute traumatic spinal cord injury among adults in the United States: an update. J Neurotrauma 2014; 31: 228-238.

6 Bjørnshave Noe B, Mikkelsen EM, Hansen RM, Thygesen M, Hagen EM. Incidence of traumatic spinal cord injury in Denmark, 1990-2012: a hospital-based study. Spinal Cord 2015; 53: 436-440.

7 Pérez K, Novoa AM, Santamariña-Rubio E, Narvaez Y, Arrufat V, Borrell C et al. Incidence trends of traumatic spinal cord injury and traumatic brain injury in Spain, 2000-2009. Accid Anal Prev 2012; 46: 37-44.

8 Nijendijk JHB, Post MWM, van Asbeck FWA. Epidemiology of traumatic spinal cord injuries in the Netherlands in 2010. Spinal Cord 2014; 52: 258-263.

9 Chamberlain JD, Deriaz O, Hund-Georgiadis M, Meier S, Scheel-Sailer A, Schubert M et al. Epidemiology and contemporary risk profile of traumatic spinal cord injury in Switzerland. Inj Epidemiol 2015; 2: 28.

10 Majdan M, Brazinova A, Mauritz W. Epidemiology of traumatic spinal cord injuries in Austria 2002-2012. Eur Spine J 2016; 25: 62-73.

11 National Spinal Cord Injury Statistical Center (NSCISC) [Internet]. Birmingham (AL): University of Alabama; 2015. 2015 Annual Statistical Report. Complete Public Version Available from https:/www.nscisc.uab.edu/PublicDocuments/reports/pdf/2015\%20NSCISC \%20Annual\%20Statistical\%20Report\%20Complete\%20Public\%20Version.pdf.

12 Shingu H, Ohama M, Ikata T, Katoh S, Akatsu T. A nationwide epidemiological survey of spinal cord injuries in Japan from January 1990 to December 1992. Paraplegia 1995; 33: 183-188.

13 Lee BB, Cripps RA, Fitzharris M, PC Wing PC. The global map for traumatic spinal cord injury epidemiology: update 2011, global incidence rate. Spinal Cord 2014; 52: 110-116.

14 DeVivo M, Biering-Sørensen F, Charlifue S, Noonan V, Post M, Stripling T et al. International spinal cord injury core data set. Spinal Cord 2006; 44: 535-540.

15 Kirshblum SC, Burns SP, Biering-Sørensen F, Donovan W, Graves DE, Jha A et al. International standards for neurological classification of spinal cord injury (revised 2011). J Spinal Cord Med 2011; 34: 535-546.

16 Sabre L, Remmer S, Adams A, Vali M, Rekand T, Asser T et al. Impact of fatal cases on the epidemiology of traumatic spinal cord injury in Estonia. Eur J Neurol 2014; 22 768-772.

17 Burns AS, Lee BS, Ditunno JF, Tessler A. Patient selection for clinical trials: the reliability of the early spinal cord injury examination. J Neurotrauma 2003; 20 477-482.

18 Franceschini M, Cerrel-Bazo H, Lauretani F, Agosti M, Pagliacci MC. Age influences rehabilitative outcomes in Spinal Cord Injury patients. Aging Clin Exp Res 2011; 23 202-208. 